\title{
Opinião pública, estratégia presidencial e ação do congresso no Brasil: "quem manda?"
}

\author{
Carlos Pereira \\ Michigan State University, Estados Unidos, e Fundação Getúlio Vargas
}

Timothy Power

Florida International University, Estados Unidos

Lúcio Rennó

University of Arizona, Estados Unidos

\begin{abstract}
Resumo
A relação entre o comportamento da elite política e as preferências gerais da população está no cerne de discussões sobre democracia representativa. Porém, pouco se sabe sobre quem influencia quem e quanto tempo demora para que tal influência seja sentida. Este artigo apresenta resultados a partir de um conjunto de dados organizados em série temporal que permite verificar a relação entre o clima da opinião pública, a escolha presidencial de instrumentos de governo (legislação extraordinária versus ordinária) e o apoio do congresso às iniciativas dos presidentes no Brasil. Foram coletadas observações mensais sobre a popularidade do presidente, padrões de votação nominal no congresso e uso de medidas provisórias, e da legislação comum, pelo executivo. Esse conjunto de dados permitiu testar, usando técnicas de séries temporais, o impacto dessas variáveis umas sobre as outras e a defasagem temporal necessária para que esses impactos se tornem significativos.
\end{abstract}

Palavras-chave: opinião pública, executivo, legislativo, série temporal.

\begin{abstract}
The relationship between elite behavior and mass preferences is in the essence of discussions about representative democracy. However, very little is known about who influences whom and how long it takes for such influence to be felt. This article presents results from a time-series dataset that allows us to verify the relationship between the mood of public opinion, presidents' choice of policy making instrument (extraordinary vs. ordinary legislation) and congressional support to presidents' policy initiatives in Brazil. We collected monthly observations of presidential popularity, patterns of roll-call voting in congress and presidents use of "medidas provisórias" as well as regular legislation. This dataset allows us to test, using time-series techniques, the impact of these variables on each other and the amount of lags it takes for these impacts to become significant.
\end{abstract}

Keywords: public opinion, executive, legislative, time-series. 


\section{Introdução}

A relação entre o comportamento da elite política e preferências gerais da população é central para o debate sobre a representação política. Tornou-se senso comum que, em regimes democráticos, eleições competitivas deveriam forçar as elites governantes a responder às pressões populares. Em uma poliarquia, essas elites são obrigadas a levar bem mais em conta as preferências dos cidadãos do que em outros regimes, aumentando assim a accountability. Nessa concepção está implícita a idéia de que os políticos deveriam reagir ao clima da opinião pública, em certa medida baseando suas ações nas preferências dos eleitores. Porém, essa é uma proposição que precisa ser examinada antes que assumida.

Com a ascensão das modernas pesquisas de opinião, o debate tomou novas direções, porque tornou-se muito mais fácil para os políticos identificar o que o público quer e, desse modo, responder de acordo. Na era da informação, governar tornou-se - mais do que em qualquer outra época da história - um processo interativo. O enigma teórico é: quem comanda o processo? É o interesse público que define a agenda das mudanças de políticas, como afirma a teoria tradicional do interesse público? Ou a opinião pública é simplesmente reflexo de ações anteriores dos políticos, como sustenta a economia política positiva? Ou ainda, poderíamos considerar um feedback recíproco em que as ações dos políticos geram reações populares que, por sua vez, assumem as formas de novos inputs ao sistema político, mudando assim as futuras ações dos representantes? Aqui, examinamos algumas dessas questões usando uma série temporal de dados com observações mensais de 1988 a 1998 no Brasil.

Ao investigar as inter-relações causais entre ação do executivo, comportamento do legislativo e opinião pública, abrimos espaço para a possibilidade de que o impacto da opinião pública sobre o comportamento da elite política não seja necessariamente imediato. As reações populares podem demorar mais tempo para afetar as decisões dos políticos porque o curso de absorção dos inputs nas democracias é lento. Em regimes democráticos, existem numerosas instituições intermediárias que filtram as demandas e muitas dessas instituições operam em condições de alta viscosidade. Além disso, a democracia se caracteriza por loci concorrentes de autoridades decisórias. Pode acontecer que a velocidade com que os inputs penetram no sistema varie conforme os poderes do Estado. Além disso, o impacto (ou falta de) da opinião pública sobre o comportamento da elite pode indicar também que os políticos estão mais isolados da pressão popular.

O lado "bom" desse insulamento é que ele pode abrir espaço para decisões mais racionais e responsáveis. Em tais casos, há um atraso no impacto da opinião pública sobre as decisões dos políticos. Um cenário mais perturbador é aquele em que o comportamento da elite pode estar quase completamente isolado das reações 
da opinião pública. Esse cenário está muito relacionado às descrições da "democracia delegativa" na América Latina, em que os freios e contrapesos são fracos e os eleitores não conseguem que seus representantes respondam por seus desempenhos em seus cargos (O'DONNELL, 1994). O segredo, então, não está apenas em descobrir se a opinião pública afeta as escolhas dos políticos, mas também em revelar o marco temporal em que isso acontece.

Criamos uma série temporal de dados que nos permite isolar as interrelações entre a opinião pública, a escolha dos presidentes quanto aos instrumentos de governo (legislação extraordinária versus ordinária) e apoio do congresso às iniciativas presidenciais no Brasil. Coletamos observações mensais sobre a popularidade do presidente, padrões de votação nominal no congresso e o uso presidencial de medidas provisórias, além de legislação comum ${ }^{1}$. Esse conjunto de dados nos permite testar, usando técnicas de séries temporais, a influência da opinião pública sobre o comportamento presidencial e do legislativo, e também como a opinião pública reage às decisões dos políticos. Tratamos de duas questões específicas em relação a esses padrões de influência. Primeiro, quão sensível é cada ator político em relação aos outros? Essa questão possui uma dimensão temporal: queremos saber quanto tempo demora para que a opinião pública reaja às ações dos governantes. A segunda questão está relacionada com processos de memória. Quanto tempo dura o impacto de cada um desses atores sobre o outro? Há um impacto duradouro do comportamento do presidente e do congresso sobre a opinião pública, ou ele é esquecido rapidamente?

O Brasil é um caso interessante para esse estudo devido ao caráter de transição de seu regime. Com efeito, a instabilidade foi a marca da história política brasileira até o período democrático mais recente, que começou em 1985 e teve eleição direta para presidente somente a partir de 1989. Além disso, como em muitos outros países recentemente democratizados, o legado da ditadura não desapareceu totalmente e a natureza da representação pós-autoritarismo tem sido duramente criticada.

Três problemas em particular a respeito da representação estão sempre em discussão no Brasil. Primeiro, há uma preponderância do poder executivo no processo de implementação de políticas públicas. Os presidentes possuem imenso poder na formulação da agenda e, em geral, obtêm o que querem do congresso (FIGUEIREDO e LIMONGI, 1999). Em segundo lugar, há uma idéia muito difundida de que os políticos estão isolados da pressão popular, graças especialmente ao uso da representação proporcional com lista aberta, com distritos de alta magnitude

\footnotetext{
${ }^{1}$ Gostaríamos de agradecer a Argelina Figueiredo e Fernando Limongi pela permissão para usar os dados do CEBRAP - Centro Brasileiro de Planejamento e Análise - sobre votações nominais (versão 2000).
} 
nas eleições legislativas (MAINWARING, 1991). Em terceiro lugar, reza a crença "popular" (em relação à qual somos agnósticos) que na democracia brasileira os eleitores têm memória incrivelmente curta. Supõe-se que aquilo que os políticos fazem hoje é facilmente esquecido no futuro e não afeta o julgamento dos eleitores em relação aos candidatos.

Reunindo essas três observações repetidas com freqüência, o retrato estilizado da democracia brasileira que emerge não é muito lisonjeiro: os presidentes são todo-poderosos, os legisladores estão fora do alcance da opinião pública e a vontade popular é prejudicada pela inconsistência e pela perda de memória. Observamos que histórias similares foram contadas sobre muitos outros regimes pós-autoritários, e modelos de democracia delegativa (O'DONNELL, 1994) e neopopulismo (WEYLAND, 1996) enfatizam as raízes fracas da representação e a maleabilidade da opinião pública. Portanto, isolar as inter-relações causais entre os comportamentos do executivo e do legislativo e a opinião pública é um primeiro passo necessário para compreender as formas emergentes de representação política, não somente no Brasil, mas em todas as novas democracias.

\section{Teoria}

A definição de representação preferida por Pitkin é "agir por" (1967). Uma visão normativa da representação como a dessa autora compreende candidatos conscientes das demandas populares e que agem em nome de seus eleitores. Isso implica que a opinião pública deveria influenciar as escolhas e decisões dos representantes. Além disso, a opinião pública também deve estar consciente do que os políticos fazem e avaliar se o que estão fazendo é de interesse público. Segue-se daí a idéia de accountability, como justiça para os políticos que não respondem às demandas populares. A falta de sensibilidade para essas demandas é punida; essa é a essência da accountability (PRZEWORSKI, STOKES e MANIN, 1999).

Quando delegam as tarefas de representação, os eleitores gostariam de dar aos políticos amplos poderes e liberdade que thes possibilitasse cumprir efetivamente sua missão. Mas devido às assimetrias de informação e aos custos do monitoramento inerentes a essas relações, os eleitores correm o risco de que esse poder delegado possa ser usado na busca de resultados que venham a prejudicar seus interesses. Em outras palavras, uma vez escolhidos pelos eleitores, os políticos podem se entregar a um comportamento oportunista ex post pelo simples fato de que os "principais" (os eleitores) não podem fazer que se cumpra de modo perfeito e sem custo um compromisso ex ante digno de crédito assumido pelos "agentes" (os políticos) de agir em defesa dos melhores interesses dos "principais". 
PEREIRA, C.; POWER, T.; RENNÓ, L. Opinião pública, estratégia presidencial e ...

Adicionalmente, como observou Manin (1997), os políticos não são obrigados por lei a serem fiéis a suas plataformas. Em nenhuma democracia existente os representantes estão sujeitos a instituições obrigatórias. Ou seja, ao mesmo tempo em que podem querer dar ao governo alguma amplitude para governar, os eleitores também prefeririam que os governos fossem fiéis às suas promessas. Porém, “o que quer que os eleitores decidam fazer, os políticos escaparão às vezes do controle deles (...) a accountability não é suficiente para induzir a representação quando os eleitores têm informações incompletas" (PRZEWORSKI, 1998).

Um dilema que os políticos enfrentam é o de se devem ser sensíveis (responsive) ou responsáveis (responsable). Aqueles que são sensíveis às demandas e mudanças de curto prazo do humor público podem não ser necessariamente responsáveis quanto às políticas públicas de longo prazo (STOKES, 2001b). A responsabilidade pode atrapalhar a capacidade dos políticos de responder de imediato às pressões populares. Isso acontece especialmente nos países em desenvolvimento, onde a necessidade de políticas impopulares na forma de planos de estabilização recessivos, a fim de combater a inflação, tornou-se imperativa no passado recente (HAGGARD e KAUFMANN, 1992). Portanto, os políticos responsáveis, aqueles que pensam em termos de longo prazo e da geração de uma base para o crescimento sustentável no futuro, podem ser punidos no curto prazo pela dureza de suas decisões.

Susan Stokes e vários outros autores tratam dessas questões e indicam que os eleitores usam critérios diferentes quando chega o momento de cobrar dos políticos (STOKES, 2001a). Eles podem ter uma abordagem intertemporal, em que as dificuldades do presente são toleradas em nome da bonança no futuro. Podem também pôr a culpa das dificuldades presentes não no governante atual, mas no legado de governos anteriores ou em crises internacionais. Além disso, os eleitores podem compreender que as promessas de campanha não foram cumpridas porque os candidatos não tinham então informações completas sobre a situação do país. Todas essas formas de avaliar os políticos levam a situações em que os governantes não são necessariamente punidos pelas dificuldades do momento. Não obstante, são formas de avaliação baseadas em como os políticos justificam suas ações. Como Pitkin argumentou antes, em termos levemente distintos, é possível enganar algumas pessoas por algum tempo, mas não se pode enganar todo mundo durante todo o tempo. Enquanto os políticos são capazes de justificar suas ações e apresentá-las como sendo em nome do interesse público, e o público as aceita, a representação e a accountability estão em funcionamento. 
São abundantes os casos de não cumprimento de promessas. Stokes estudou amplamente os casos de presidentes latino-americanos que implementaram políticas totalmente diferentes de suas promessas de campanha e que depois receberam o apoio popular e acabaram por levar à reeleição do governante (STOKES, 2001b). Isso é uma indicação de que os políticos possuem de fato uma liberdade de movimento quando fazem suas escolhas. No século XVIII, Burke já afirmara que se deveria conceder aos políticos certa margem de manobra: os representantes não precisam consultar os representados sobre cada decisão. $\mathrm{Na}$ verdade, uma vez que os representantes estão mais bem informados sobre as questões políticas e os assuntos atuais do que a maioria da população, são eles que devem tomar as decisões. Até recentemente na história democrática, a consulta direta à população era um tanto limitada em alcance. Os recursos para saber o que os cidadãos queriam eram muito limitados, obstruindo um processo interativo de troca de informações. Isso não significa, no entanto, que os políticos não fossem punidos por seus erros. De novo, a chave para a representação, para esses autores, é a capacidade dos eleitores de fazer com que os governantes respondam por suas ações.

Em uma direção oposta, Kalt e Zupan (1984) identificam nessa assimetria de informação entre eleitores e representantes a oportunidade para que os políticos não sigam nem os interesses de seus eleitores nem os grupos de pressão, mas o interesse público - ou o que eles chamam de ideologia. Ou seja, os políticos têm muito mais liberdade do que se costuma atribuir a eles. Nesse contexto, o interesse público deriva do fato de que os legisladores votam não naquilo que seus eleitores se preocupam, mas em como acreditam que o mundo deveria funcionar. Stigler (1971) chamou esse comportamento de "motivo de consumo" (isto é, o dever cívico de servir ao interesse do público), em contraposição ao "motivo de investimento" de aumentar a própria riqueza ou as chances de reeleição.

Em contraste com essa visão de dominação dos políticos, Denzau e Munger (1986) desenvolveram um modelo da oferta de políticas públicas nos Estados Unidos a fim de testar quais grupos de interesse e quais conjuntos de eleitores têm maior probabilidade de serem atendidos pelos políticos. A lógica básica desse modelo é a seguinte: "os resultados das políticas dependem das vantagens comparativas dos participantes. A vantagem comparativa, nesse contexto, depende do valor do que cada conjunto de agentes do modelo tem a oferecer aos outros (...) Os legisladores buscam maximizar votos, o que pode ser obtido seja pelo fornecimento de políticas que os eleitores aprovam, seja por atender a grupos de interesse em troca de recursos de campanha que produzam votos. Especificamente, quanto mais produtivo o esforço de um legislador ou menos hostis os eleitores a determinada política, mais baixo o preço mínimo que um grupo de interesse deve pagar em troca". 
Atualmente, a proliferação das pesquisas de opinião pública e a expressiva melhora das técnicas de amostragem oferecem informações mais do que suficientes para os políticos sobre o que o público quer (BREHM, 1996). A cada semana, pesquisas indicam a satisfação dos eleitores com os governantes e suas opiniões sobre políticas específicas. Isso acontece não apenas nos países desenvolvidos da América do Norte e da Europa Ocidental, mas também nas novas democracias da América Latina, Europa Oriental e Ásia. A pesquisa de opinião tornou-se a expressão mais citada da vontade popular, a materialização da voz popular. $O$ processo interativo entre representante e eleitor, que outrora estava restrito às reuniões na prefeitura e coisas semelhantes, está agora generalizado para toda a sociedade. É inquestionável que os políticos prestam atenção às pesquisas. Poucos legisladores podem passar sem recorrer a elas e nenhum governante moderno vive sem uma empresa de pesquisa por perto. As pesquisas de opinião se tornaram uma ferramenta cotidiana de governo.

Porém, a discussão acadêmica sobre como a opinião pública afeta as ações dos políticos e vice-versa ficou, em geral, restrita aos Estados Unidos, onde existem vários estudos sobre o que leva os representantes a se afastar das demandas de seus eleitores, a maioria adotando modelos espaciais para representar mudanças de posições (ROSEMBERG e SANDERS, 2000; FRANCIS e KENNY, 1996). Há também estudos sobre como as ações governamentais são afetadas pelos ciclos do negócio eleitoral e como as políticas públicas, em especial na esfera econômica, afetam o voto e as visões dos eleitores sobre os políticos (STOKES, 2001a; LEWIS. BECK, 1988; NORDHAUS, 1975). Embora esses estudos sejam valiosos, poucas pesquisas examinaram como a visão que o público tem do desempenho dos governantes pode influenciar as escolhas futuras desses governantes. Uma questão central desse debate é: quem estabelece a agenda? Quem manda? É o público que orienta o comportamento dos políticos, ou o contrário, ou seja, o público é apenas reativo? Há um feedback recíproco em que o comportamento dos políticos afeta a avaliação que o público faz dos governantes que, por sua vez, afeta as decisões futuras dos políticos? Por fim, diferentes poderes governamentais reagem de modo diferente à opinião pública²?

Essas questões foram examinadas para o caso dos Estados Unidos por Edwards e Wood (1999). Neste estudo, os autores comparam as influências relativas da presidência, do congresso e da mídia sobre a agenda política. Os autores questionam o consenso crescente de que o presidente é o ator mais importante no processo norte-americano de elaboração de políticas. Em outras

\footnotetext{
${ }^{2}$ Outra questão interessante é como as escolhas presidenciais se relacionam com o apoio dos deputados ao presidente e como o apoio do congresso afeta as escolhas dos presidentes. Ver Pereira, Power e Rennó (2005) para uma discussão das relações executivo-legislativo.
} 
palavras, os autores levantam dúvidas sobre a concepção do governo centrada na presidência. O objetivo é enfocar "a capacidade do presidente de afetar os padrões de atenção de outros atores institucionais importantes no sistema político" (EDWARDS e WOOD, 1999, p. 327). Em outros termos, a questão principal deles é: quem influencia quem? Eles utilizam análise de conteúdo nos discursos presidenciais, em noticiários de televisão e em audiências públicas no congresso para contar a quantidade de vezes em que certo tópico é mencionado.

Uma vez que não têm nenhuma justificação teórica para especificar a priori a direção da causalidade entre as variáveis acima mencionadas, esses autores não colocam muitas restrições na especificação do seu modelo. Edwards e Wood permitem que os dados falem por eles mesmos, a fim de revelar a direção da causalidade. Por esta razão, utilizam o método de Granger, no qual é feita uma regressão com uma variável dependente sobre valores defasados dela mesma, bem como de outras variáveis dependentes no sistema. Além disso, todas as variáveis em um mesmo ponto no tempo são consideradas endógenas. Portanto, valores anteriores de atenção presidencial podem determinar valores futuros de atenção do congresso, mas pode haver também feedback recíproco entre congresso e presidentes. Uma das conclusões centrais é que há uma quantidade considerável de inércia nas agendas desses três diferentes atores, ou seja, a agenda anterior de um certo ator determina fortemente sua agenda futura e dilui a influência dos outros atores.

A questão fundamental que nos interessa aqui é como relações similares (entre escolha presidencial de instrumento decisório, clima no congresso e opinião pública) ocorrem no Brasil.

\section{Dados, enigmas e análises}

Para aplicar o programa de pesquisa de Edwards e Wood ao caso brasileiro, coletamos um conjunto de dados de medidas mensais de comportamento dos poderes públicos e da opinião pública entre 1988 e 1998. Nossas três variáveis principais são: utilização presidencial do poder de decreto, apoio legislativo às iniciativas governamentais e popularidade do presidente. A primeira dessas variáveis, o uso da autoridade de decretar pelo executivo, é nosso indicador das ações dos presidentes e é expressa pela razão entre as medidas provisórias e as leis normais apresentadas pelo presidente. Em outras palavras, nossa "razão de dependência em decretos" mede a freqüência com que os presidentes apelam a meios extraordinários de definição de políticas. Essa variável não contém informações sobre as políticas em si mesmas. É claro que seria preferível para nós ter um indicador do conteúdo das medidas provisórias, mas infelizmente esse indicador não está atualmente à disposição. Porém, a "razão de dependência em 
decretos" pode também ser vista como uma medida das tentativas do presidente de comandar os outros dois atores e assim obter um papel decisivo de estabelecimento da agenda no sistema político. Quanto mais alto o valor da "razão de dependência em decretos", mais autônomo busca ser o presidente. Quanto menor esse valor, mais o congresso é incorporado ao processo de decisão política e menos autônomo o presidente pode esperar ser.

A segunda variável é um indicador de apoio legislativo ao presidente. Ela revela o clima geral do congresso em relação às propostas do executivo. Valores mais altos dessa variável indicam que as propostas do presidente obtêm aprovação do congresso e valores menores indicam que o congresso é mais resistente. Por fim, nossa terceira variável, a popularidade do presidente, é um indicador da avaliação que os eleitores fazem do desempenho presidencial.

Nossa escolha de variáveis reflete o fato de que o Brasil é um sistema político centrado na presidência. O poder executivo brasileiro possui consideráveis poderes de estabelecer agenda e tem a última palavra nas alocações orçamentárias. O congresso costuma ser visto como reativo e as políticas iniciadas ali restringem. se usualmente a áreas específicas, tais como políticas sociais e distributivas (FIGUEIREDO e LIMONGI, 1999). Portanto, não há dúvida de que o presidente é o principal ator político no Brasil. Porém, pode o congresso ser simplesmente ignorado? A opinião pública afeta de alguma forma as escolhas do presidente? Qual é a relação de fato entre esses três atores centrais no Brasil?

Os dados vão do último ano e meio do governo José Sarney ao final do primeiro mandato de Fernando Henrique Cardoso. São os primeiros dez anos da promulgação da Constituição de 1988 que marcou o retorno final do Brasil ao pleno regime democrático. Durante esse período, houve quatro presidentes diferentes. Sarney foi seguido por Fernando Collor de Melo, o primeiro presidente eleito por voto direto depois de 29 anos, que assumiu em 1990. Collor administrou o país até 1992, quando renunciou para não sofrer um impeachment devido a acusações de corrupção. Seu vice-presidente, Itamar Franco, assumiu e governou até dezembro de 1994. Ele conseguiu fazer seu sucessor, o então ministro da fazenda Fernando Henrique Cardoso, eleito graças ao sucesso do Plano Real de estabilização monetária.

Como Amorim Neto et al. (2003) e Pereira, Power e Rennó (2005) argumentaram, o governo $\mathrm{FHC}$ representou uma mudança significativa em relação aos anteriores. Durante seu mandato, ele conseguiu montar uma coalizão majoritária relativamente estável no congresso. É verdade que teve de se envolver em negociações controversas com o congresso e que algumas de suas principais propostas políticas não foram aprovadas (AMES, 2001). Porém, em comparação com períodos anteriores, a relação entre executivo e legislativo durante seu governo foi menos errática e conflituosa. 
Os níveis de popularidade de FHC também foram em geral mais altos do que os dos governos anteriores. Devido, em grande parte, ao sucesso do Plano Real, seu apoio popular flutuou menos e permaneceu relativamente alto até o final de seu primeiro mandato, em dezembro de $1998^{3}$. Por outro lado, os presidentes anteriores a FHC enfrentaram não apenas níveis mais baixos de popularidade em geral, como também níveis mais flutuantes de apoio público.

Portanto, nossos dados permitem captar uma variação ao longo do tempo de estilos de governo dos presidentes, de suas relações com o congresso e de seus níveis de popularidade. Isso proporciona uma excelente oportunidade para avaliar como cada um desses fatores afeta os outros. A opinião pública molda as ações dos presidentes e dos legisladores? Ou ocorre o oposto, e a opinião pública é uma reação ao que os presidentes e deputados federais fazem? Além disso, quanto tempo demora para que cada um desses atores reaja? Por sua vez, essa reação influencia depois as ações dos governantes?

Se há um feedback recíproco, ou seja, a opinião pública influencia depois as escolhas dos políticos, isso indica que estes estão respondendo às demandas populares. Caso contrário, se a opinião pública não afeta de modo algum as escolhas dos políticos, trata-se de uma clara indicação de que os representantes têm grande liberdade para fazer o que julgam melhor. Isso, sem dúvida, representa um dilema para a governança democrática. Se as opiniões dos eleitores não se infiltram no processo de tomada de decisões, a representação, tal como a concebemos, deixa de existir?

Como não existem expectativas teóricas claras a respeito da direção da causalidade, submetemos inicialmente os dados a uma série de testes de causalidade de Granger bivariados. Esses testes permitem-nos verificar qual variável causa as outras e com que forma de estrutura de defasagem. É um teste apropriado a situações em que os vetores de causalidade ou não são definidos claramente ou a causalidade apresenta dupla direção. Portanto, temos condições de identificar quão sensível um ator é às preferências de outro (quanto tempo um ator demora para reagir ao outro) e como os processos de memória desses atores funcionam (quanto tempo perdura o impacto). Enfocamos aqui principalmente as relações entre governantes eleitos e opinião pública, ao passo que em outro lugar, tratamos da relação entre executivo e legislativo (PEREIRA, POWER e RENNÓ, 2005).

A Tabela 1 ilustra a relação entre popularidade presidencial (opinião pública), escolhas presidenciais e apoio do congresso com uma defasagem de um mês. Essa é a reação mais imediata que cada um desses atores pode apresentar às ações dos outros. O único impacto estatisticamente significante é o da opinião pública sobre a ação do congresso. Isso indica que o congresso reage com muita

\footnotetext{
${ }^{3} \mathrm{FHC}$ foi muito impopular em seu segundo mandato, que não entra nesta análise.
} 
PEREIRA, C.; POWER, T.; RENNÓ, L. Opinião pública, estratégia presidencial e ...

rapidez à aprovação presidencial. O congresso presta atenção à popularidade do presidente, pois esse é o fator que determinará se o congresso será um ator reativo ou proativo no jogo da política. Em um ambiente institucional no qual o presidente predomina, a melhor aposta para a ascendência do legislativo é um presidente com níveis mais baixos de apoio popular.

Tabela 1

Causalidade de Granger entre opinião pública, estratégia presidencial e escolhas dos deputados federais com defasagem de um mês. Brasil, 1988-1998

\begin{tabular}{|l|l|c|c|}
\hline Variável causal & Variável explicada & Teste F & Prob > F \\
\hline Apoio do congresso & Popularidade presidencial & 0,238 & 0,626 \\
\hline Estratégia presidencial & Popularidade presidencial & 0,770 & 0,382 \\
\hline Popularidade presidencial & Estratégia presidencial & 0,889 & 0,348 \\
\hline Popularidade presidencial & Apoio do congresso & $\mathbf{4 , 4 9}$ & $\mathbf{0 , 0 3 6}$ \\
\hline
\end{tabular}

É interessante também avaliar quanto tempo demora para que a influência da opinião pública no congresso se dissipe. Para tanto, investigamos como cada fator afeta o outro com diferentes especificações de defasagem. Primeiro, procedemos a avaliação de quão duradoura é a influência do congresso na opinião pública.

A Tabela 2 indica como o apoio do congresso às iniciativas políticas presidenciais afeta a aprovação popular do presidente. Fica claro que a popularidade presidencial é afetada pelo apoio do legislativo ao presidente com defasagens de dois, três e quatro meses. Ainda que a opinião pública não reaja imediatamente às ações do congresso, como mostra a Tabela 1 , ele o faz depois de dois, três ou quatro meses. Isso significa que não somente o comportamento do congresso afeta como os eleitores percebem o presidente, como também que esse efeito é duradouro. Parece que o comportamento do congresso influencia a opinião dos eleitores sobre quão bem o presidente está fazendo seu trabalho.

Tabela 2

Causalidade de Granger do apoio do congresso sobre a popularidade do presidente em diferentes momentos do tempo. Brasil, 1988-1998

\begin{tabular}{|l|l|l|c|c|}
\hline \multicolumn{1}{|c|}{ Defasagem } & \multicolumn{1}{|c|}{ Variável causal } & \multicolumn{1}{|c|}{ Variável explicada } & Teste $\mathbf{F}$ & Prob > F \\
\hline 2 & Apoio do congresso & Popularidade presidencial & 4,44 & 0,014 \\
\hline 3 & Apoio do congresso & Popularidade presidencial & 4,52 & 0,000 \\
\hline 4 & Apoio do congresso & Popularidade presidencial & 4,55 & 0,000 \\
\hline
\end{tabular}


Na Tabela 3, exploramos o impacto da escolha presidencial sobre a opinião pública. O objetivo é avaliar se as estratégias de elaboração de políticas afetam as preferências do público em geral. De novo, não podemos dizer nada sobre os conteúdos das políticas; nossa medida de estratégia do executivo mede simplesmente se o presidente está tentando implementar sua iniciativa por meios extraordinários (situação em que o presidente estaria utilizando ao máximo a capacidade de determinar a agenda que Ihe é permitida pela constituição) ou por meios ordinários (em que o congresso se torna parceiro do presidente ao considerar as propostas do executivo). A Tabela 3 deixa claro que a estratégia de elaboração de políticas seguida pelo presidente exerce muita influência sobre a configuração da aprovação presidencial. Ainda que o índice de aprovação não seja afetado imediatamente (a defasagem de um mês usada na Tabela 1 não detecta nenhum efeito), a popularidade do presidente sofre o impacto da "razão de dependência em decretos", o qual dura por até quatro meses. Isso indica que demora um pouco para que o público conheça e avalie o modus operandi do presidente, mas depois que o faz, isso influencia sua visão do presidente baseada nas estratégias de elaboração e aprovação de políticas que ele utiliza.

Tabela 3

Causalidade de Granger da estratégia presidencial sobre a popularidade do presidente em diferentes momentos do tempo. Brasil, 1988-1998

\begin{tabular}{|l|l|l|c|c|}
\hline Defasagem & \multicolumn{1}{|c|}{ Variável causal } & \multicolumn{1}{|c|}{ Variável explicada } & Teste $\mathbf{F}$ & Prob $>$ F \\
\hline 2 & Estratégia presidencial & Popularidade presidencial & 0,931 & 0,397 \\
\hline 3 & Estratégia presidencial & Popularidade presidencial & 2,30 & 0,080 \\
\hline 4 & Estratégia presidencial & Popularidade presidencial & 3,24 & 0,015 \\
\hline
\end{tabular}

Por fim, a Tabela 4 indica como a opinião pública afeta tanto a estratégia presidencial como o apoio do congresso ao executivo. Isso, como observamos antes, diz respeito a um dilema essencial na discussão sobre representação: estão os políticos isolados das demandas populares? Relembremos que na Tabela 1, que usou a defasagem de um mês, a aprovação presidencial afeta imediatamente o comportamento do congresso. A Tabela 4 deixa claro que esse impacto se dissipa rapidamente. A opinião pública afeta o apoio do legislativo ao presidente apenas de modo efêmero. Além disso, em nenhum momento a opinião pública afeta a estratégia presidencial. A opinião pública não tem nenhum efeito sobre a escolha do presidente entre instrumentos extraordinários ou ordinários de elaboração política; 
PEREIRA, C.; POWER, T.; RENNÓ, L. Opinião pública, estratégia presidencial e ...

supostamente, o executivo faz essas escolhas estratégicas independentemente do que o público pensa delas. Como sustentamos em outro lugar (PEREIRA, POWER e RENNÓ, 2005), o principal fator que afeta a escolha de instrumentos políticos pelos presidentes parece ser a capacidade do executivo de administrar uma coalizão multipartidária no congresso 4 .

Tabela 4

Causalidade de Granger da popularidade presidencial sobre o apoio do congresso e a estratégia presidencial com defasagens variadas. Brasil, 1988-1998

\begin{tabular}{|l|l|l|c|c|}
\hline Defasagem & \multicolumn{1}{|c|}{ Variável causal } & \multicolumn{1}{|c|}{ Variável explicada } & Test F & Prob > F \\
\hline 2 & Popularidade presidencial & Estratégia presidencial & 1,15 & 0,318 \\
\hline 2 & Popularidade presidencial & Apoio do congresso & 2,02 & 0,137 \\
\hline 3 & Popularidade presidencial & Estratégia presidencial & 1,20 & 0,312 \\
\hline 3 & Popularidade presidencial & Apoio do congresso & 1,36 & 0,256 \\
\hline 4 & Popularidade presidencial & Estratégia presidencial & 1,21 & 0,307 \\
\hline 4 & Popularidade presidencial & Apoio do congresso & 2,23 & 0,124 \\
\hline
\end{tabular}

Como esses resultados se sustentam numa análise multivariada? A Tabela 5 mostra o resultado da regressão de popularidade presidencial, escolha presidencial e apoio do congresso sobre valores defasados de cada uma dessas variáveis, ao lado de várias co-variáveis como inflação, desemprego, ciclo eleitoral, administração de coalizão no congresso (defasagem do tamanho do gabinete, defasagem da taxa de coalescência do gabinete e a interação entre ambas). Incluímos também controles para períodos de lua-de-mel, introdução de grandes planos econômicos, número de leis propostas pelo executivo (tamanho da agenda) e uma variável dummy para o período depois que a emenda constitucional que permitiu a reeleição para os cargos executivos foi implementada ${ }^{5}$.

\footnotetext{
${ }^{4}$ Amorim Neto (2002), cujas medidas de administração de coalizão usamos em nosso trabalho, mostrou a importância do tamanho da coalizão e da coalescência do gabinete para a manutenção da disciplina partidária dentro da facção pró-presidencial no congresso.

${ }^{5}$ Para uma discussão mais completa dessas variáveis e do modelo de estratégia presidencial referimos o leitor para nosso artigo a ser publicado no Journal of Politics. As variáveis "inflação" e "desemprego" captam a crise econômica, que foi enfrentada muitas vezes com decretos presidenciais durante o período estudado. "Plano econômico" marca, em forma dummy, os meses em que "pacotes" de novas medidas foram introduzidos com grande quantidade de decretos (Plano Collor, Plano Real, etc.). "Tamanho da agenda" controla a possibilidade de que, com o aumento do ativismo geral de um presidente, o mesmo pode acontecer com sua dependência de decretos. Não incluímos as variáveis de administração de coalizão na equação que explica a popularidade porque não há motivo teórico para acreditar que elas poderiam afetar diretamente a popularidade. Não há motivo para acreditar que o público está atento a questões de gerenciamento de campanha.
} 
Tabela 5

Coeficientes de regressão Prais-Winsten AR(1) para popularidade presidencial, estratégia presidencial e apoio do congresso. Brasil, 1988-1998

\begin{tabular}{|l|c|c|c|}
\hline Variáveis & $\begin{array}{c}\text { Popularidade } \\
\text { presidencial }\end{array}$ & $\begin{array}{c}\text { Estratégia } \\
\text { presidencial }\end{array}$ & $\begin{array}{c}\text { Apoio do } \\
\text { congresso }\end{array}$ \\
\hline Constante & $-10,9^{* *}$ & 31,0 & 12,7 \\
\hline Popularidade presidencial (com defasagem de 1 mês) & $0,89^{* * *}$ & 0,03 & $-0,01$ \\
\hline Apoio do congresso (com defasagem de 1 mês) & $0,10^{*}$ & $-0,36^{*}$ & $0,61^{* * *}$ \\
\hline Estratégia presidencial (com defasagem de 1 mês) & $0,04^{* *}$ & $-0,04$ & $-0,03$ \\
\hline Inflação (com defasagem de 1 mês) & $-0,03$ & $-0,19$ & $-0,15^{*}$ \\
\hline Desemprego (com defasagem de 1 mês) & 0,50 & $-4,30^{*}$ & $-0,30$ \\
\hline Tamanho do gabinete (com defasagem de 1 mês) & - & $2,49^{* * *}$ & 0,53 \\
\hline $\begin{array}{l}\text { Taxa de coalescência do gabinete (com defasagem de } \\
\text { mês) }\end{array}$ & - & $-0,71$ & 0,09 \\
\hline Interação & - & $-0,01$ & $-0,01$ \\
\hline Tamanho da agenda & $-0,06$ & $-0,18$ & $-0,18$ \\
\hline Plano econômico & $9,75^{\star *}$ & $32,9^{* *}$ & $23,5^{* *}$ \\
\hline Lua-de-mel & 1,52 & 14,4 & $-8,54$ \\
\hline Reeleição & 0,76 & 4,88 & $-2,68$ \\
\hline Eleição & $-1,52$ & 14,5 & 2,39 \\
\hline \hline$R^{2}$ & $0,93^{* * *}$ & $0,62^{* * *}$ & $0,62^{* * *}$ \\
\hline Estatística Durbin Watson (transformada) & 1,79 & 1,94 & 1,82 \\
\hline Rho & 0,427 & 0,023 & $-0,277$ \\
\hline \hline Tamanho da amostra & 116 & 116 & 116 \\
\hline
\end{tabular}

* significante em 0,$1 ; * *$ significante em 0,$05 ;{ }^{* * *}$ significante em 0,01

Os resultados indicam que a popularidade presidencial com defasagem, nosso substituto para opinião pública, não tem efeito estatisticamente significante sobre a escolha presidencial de instrumentos políticos e sobre o apoio do congresso às iniciativas legislativas do executivo. Os dados indicam, na verdade, que a opinião pública é mais afetada pelas ações dos políticos, ou seja, o comportamento do congresso e a escolha do presidente têm um impacto positivo e estatisticamente significante sobre a popularidade presidencial. Quanto mais o congresso apóia o presidente, mais popular este se torna. Além disso, quanto mais o presidente se utiliza de decretos, mais popular ele é. Como seria de se esperar, há também um forte componente inercial na popularidade do presidente, pois a do mês anterior determina, em larga medida, a do mês seguinte.

É interessante observar que a aprovação do presidente depende da orientação do congresso em relação a ele. Portanto, os presidentes precisam levar em conta as relações entre os poderes se estiverem interessados em sua popularidade. Essas relações afetam não somente o processo de elaboração de 
políticas, mas também o modo como os presidentes são vistos pelo público. Esse resultado fortalece as idéias sobre a influência crescente dos parlamentos na política latino-americana contemporânea (JOHNSON e CRISP, 2003).

A popularidade presidencial é também afetada pelo que os presidentes fazem. Quanto mais eles usam decretos, ou meios extraordinários de legislar, mais populares eles se tornam. As medidas provisórias têm efeito imediato e, durante o período estudado, continuavam em vigor enquanto o congresso não as rejeitasse especificamente ou não fossem votadas ${ }^{6}$. Desse modo, o público parece reagir favoravelmente às escolhas presidenciais que aceleram o processo legislativo e que têm um impacto direto e visível nas políticas públicas. Esse resultado é ainda mais notável à luz do impacto positivo da variável "plano econômico" sobre a popularidade presidencial. Todos os planos de estabilização, a partir da presidência de Sarney, foram implementados via decreto (Plano Collor, Plano Real, etc.). Foram também momentos em que os presidentes tiveram súbitos picos de popularidade porque o impacto imediato da estabilização era geralmente bem recebido pela população. Basicamente, todos os esforços para controlar a inflação foram populares entre os brasileiros no curto prazo. Mas mesmo quando controlamos os pacotes de estabilização, vemos que o uso de decretos pelo executivo contribui positivamente para a aprovação do presidente. O uso de meios extraordinários de legislação pode aumentar a popularidade porque esses meios estão geralmente associados a impactos imediatos e palpáveis sobre a vida cotidiana do cidadão médio. Eles também podem reforçar a imagem do presidente como líder ativo e decidido.

Por fim, testamos se há um impacto atrasado da popularidade presidencial nas ações dos políticos fazendo uma regressão da escolha presidencial e do apoio do congresso sobre várias defasagens de popularidade. Se há um feedback recíproco entre as ações dos políticos e a reação do público, então o impacto desta pode não ser imediato. Há provavelmente um atraso na influência da opinião pública sobre as ações dos políticos. Descobrimos que mesmo com uma estrutura de defasagem de quatro meses, a opinião pública jamais influencia o apoio do congresso ao presidente, quando se controlam outras variáveis. Por outro lado, a escolha presidencial de instrumento legislativo, como se pode ver na Tabela 6, é afetada pela popularidade do presidente com uma defasagem de dois meses. Ou seja, é preciso dois meses para que a opinião pública influencie a escolha presidencial. E esse impacto é negativo: quanto mais popular o presidente, menos provável que recorra ao poder de decretar.

\footnotetext{
${ }^{6}$ A disposição constitucional que regula as medidas provisórias foi alterada em setembro de 2001, para forçar o congresso a votá-las com mais rapidez (dentro de 120 dias) e garantir que elas expirem irreversivelmente no final desse período. Assim, não é possível comparar plenamente o período que se iniciou em setembro de $2001 \mathrm{com}$ a década examinada neste trabalho. Mais uma vez, referimos o leitor ao nosso artigo no Journal of Politics para uma descrição detalhada do poder de decreto no Brasil.
} 
OPINIÃO PÚBLICA, Campinas, Vol. XI, no 2, Outubro, 2005, p. 401-421

Tabela 6

Regressão Prais-Winsten AR(1) da estratégia presidencial com erros-padrão robustos

\begin{tabular}{|c|c|c|c|c|c|c|}
\hline Escolha presidencial & Coeficientes & $\begin{array}{c}\text { Erros-padrão } \\
\text { robustos }\end{array}$ & $\mathbf{t}$ & $P>|t|$ & [Intervalc & onfiança \\
\hline Constante & 34,35 & 37,26 & 0,92 & 0,36 & $-39,60$ & 108,29 \\
\hline $\begin{array}{l}\text { Popularidade presidencial } \\
\text { (com defasagem de } 1 \text { mês) }\end{array}$ & 0,36 & 0,29 & 1,20 & 0,23 & $-0,23$ & 0,94 \\
\hline $\begin{array}{l}\text { Popularidade presidencial } \\
\text { (com defasagem de } 2 \text { meses) }\end{array}$ & $-0,79$ & 0,37 & $-2,14$ & 0,04 & $-1,52$ & $-0,06$ \\
\hline $\begin{array}{l}\text { Popularidade presidencial } \\
\text { (com defasagem de } 3 \text { meses) }\end{array}$ & 0,15 & 0,40 & 0,37 & 0,71 & $-0,64$ & 0,93 \\
\hline $\begin{array}{l}\text { Popularidade presidencial } \\
\text { (com defasagem de } 4 \text { meses) }\end{array}$ & 0,32 & 0,26 & 1,22 & 0,23 & $-0,20$ & 0,84 \\
\hline Tamanho da agenda & $-0,14$ & 0,46 & $-0,32$ & 0,75 & $-1,05$ & 0,76 \\
\hline Reeleição & 2,01 & 8,44 & 0,24 & 0,81 & $-14,75$ & 18,76 \\
\hline Ciclo Eleitoral & 18,93 & 9,24 & 2,05 & 0,04 & 0,60 & 37,27 \\
\hline $\begin{array}{l}\text { Apoio do congresso (com } \\
\text { defasagem) }\end{array}$ & $-0,30$ & 0,22 & $-1,37$ & 0,17 & $-0,75$ & 0,14 \\
\hline $\begin{array}{l}\text { Taxa de coalescência do } \\
\text { gabinete }\end{array}$ & $-0,95$ & 0,85 & $-1,12$ & 0,27 & $-2,64$ & 0,74 \\
\hline Tamanho do gabinete & 2,14 & 0,72 & 2,98 & 0,00 & 0,71 & 3,56 \\
\hline Interação & $-0,01$ & 0,02 & $-0,68$ & 0,50 & $-0,04$ & 0,02 \\
\hline $\begin{array}{l}\text { Inflação (com defasagem de } \\
1 \text { mês) }\end{array}$ & $-0,16$ & 0,22 & $-0,72$ & 0,47 & $-0,60$ & 0,28 \\
\hline $\begin{array}{l}\text { Desemprego (com } \\
\text { defasagem de } 1 \text { mês) }\end{array}$ & $-3,97$ & 2,21 & $-1,79$ & 0,08 & $-8,36$ & 0,42 \\
\hline Lua-de-mel & 10,90 & 9,73 & 1,12 & 0,27 & $-8,42$ & 30,21 \\
\hline Plano econômico & 32,73 & 15,46 & 2,12 & 0,04 & 2,04 & 63,42 \\
\hline Rho & $-0,03$ & & & & & \\
\hline
\end{tabular}

Número de observações $=113$

$\mathrm{F}(16,97)=40,52$

Prob $>F=0,0000$

$\mathrm{R}^{2}=0,5709$

Root MSE $=20,147$

Estatística Durbin-Watson (original) $=2,017841$

Estatística Durbin-Watson (transformada) $=1,969450$

O feedback recíproco entre escolha presidencial de instrumento de elaboração de políticas e popularidade do presidente tem o seguinte formato: quando os presidentes implementam políticas por meios extraordinários, que têm um efeito imediato, há respostas positivas imediatas do público, na forma de aumento da popularidade. Porém, na esteira do aumento da popularidade vem uma redução do uso de medidas provisórias pelo presidente. Ou seja, a popularidade 
gerada pela política de efeito imediato é depois usada pelo presidente para tentar implementar políticas no congresso pelas vias ordinárias, o que significa utilizar projetos de leis, em vez de decretos. Em suma, formas ágeis de governar geram uma reação imediata do público que é depois absorvida pelo executivo ao conceber sua estratégia legislativa.

\section{Conclusão}

Os resultados de nossa análise apontam para quatro conclusões principais sobre as inter-relações entre aprovação do presidente, estratégia presidencial de definição e aprovação de políticas e apoio do legislativo ao presidente:

1. Os testes bivariados de Granger mostram que o congresso reage com rapidez à imagem pública do presidente. Porém, o efeito é efêmero por natureza; dentro de dois meses, o impacto da opinião pública sobre o congresso se reduz à insignificância. Isso significa que se a popularidade presidencial se mantiver constante, permanecerá na agenda do congresso, reatualizada a cada dois meses. De fato, é uma mudança na popularidade que causa um efeito cascata que é absorvido pelo clima geral do congresso depois de um certo período de tempo. Os testes multivariados, por outro lado, não revelam nenhum impacto da popularidade presidencial sobre o apoio do congresso ao presidente com defasagens de até quatro meses. Assim, em um teste mais robusto, o efeito some e é suplantado por outros fatores.

2. O grau de apoio do congresso ao presidente influencia a visão dos eleitores sobre o desempenho do presidente. Isso confirma nossas expectativas, e contradiz parte do senso comum no Brasil, ou seja, que os eleitores são capazes de ser minimamente informados sobre seus representantes e empregam sim cálculos sofisticados quando tomam suas decisões, especialmente sobre o presidente.

3. A estratégia de elaboração de políticas utilizada pelo presidente influencia muito sua aprovação pelo público. Isso é um outro sinal de que o público está atento e reage às ações presidenciais, reforçando nosso ponto sobre o erro de se considerar o eleitorado brasileiro como sem sofisticação e atenção.

4. Há também resultados mistos quanto ao impacto da opinião pública sobre a escolha de instrumentos extraordinários ou ordinários de elaboração de política pelo presidente. A análise bivariada de Granger não indica nenhum impacto da popularidade sobre essa escolha do presidente. O teste multivariado com defasagens de até quatro meses mostra que há um impacto retardado da opinião pública sobre a escolha presidencial, gerando feedback recíproco entre popularidade e ação presidencial ${ }^{7}$. Isso é uma indicação de que as demandas populares não se

\footnotetext{
7 Há uma importante advertência a fazer quanto a esse resultado: com uma defasagem de quatro meses,
} 
infiltram imediatamente dentro do processo democrático de tomada de decisão, o que é perfeitamente normal de acordo com nossas expectativas teóricas. De fato, é um sinal da responsabilidade dos últimos presidentes brasileiros em relação à política pública, fugindo das "sensibilidades" imediatistas típicas das administrações populistas do passado (DORNBUSCH e EDWARDS, 1991).

Tomadas em conjunto, essas quatro conclusões sugerem que a opinião da população parece ser mais reativa do que proativa. O apoio do congresso ao presidente influencia a opinião pública sobre o presidente. Os eleitores têm perfeita consciência do apoio ou não do congresso ao executivo e isso molda sua visão da competência do presidente. Além disso, a análise multivariada indica que há um feedback recíproco entre as escolhas que o presidente faz de instrumentos legislativos e a popularidade presidencial. Isso sugere que precisamos repensar a acusação tão repetida de que os eleitores brasileiros não lembram nada a respeito de seus representantes eleitos depois que os mandam para Brasília. Eles podem não ter um alto nível de conhecimento sobre cada um dos legisladores e seu comportamento nas votações mas, no agregado, eles certamente estão conscientes da postura geral do congresso em relação ao presidente. $E$, o que é mais importante, nossos resultados sugerem que os eleitores usam a informação para avaliar o desempenho do presidente. Trata-se de uma importante restrição à hipótese de que a representação no Brasil é prejudicada pela suposta falta de memória dos eleitores.

O mesmo se aplica ao impacto da estratégia legislativa presidencial sobre a avaliação do presidente pelo público. Com uma pequena defasagem, os eleitores ficam sensíveis ao estilo de governo do presidente, que pode se inclinar para instrumentos ordinários ou extraordinários. De novo, eles utilizam supostamente essa nova informação para avaliar o chefe do executivo.

A questão final e central aqui tratada é como a opinião pública afeta a estratégia presidencial e o apoio do congresso ao presidente no longo prazo. Encontramos resultados contraditórios sobre a existência dessa influência. 0 impacto da popularidade presidencial sobre a ação do congresso é, na melhor das hipóteses, transitório. Ademais, a escolha pelos presidentes de seu instrumento legislativo preferido parece estar isolada da visão popular sobre o desempenho dos presidentes. Encontramos impacto estatisticamente significante da popularidade sobre a escolha presidencial somente quando utilizamos uma defasagem de pelo menos dois meses. Isso aponta para a existência de um possível feedback recíproco entre escolha presidencial de instrumento legislativo e opinião pública. De início, a 
PEREIRA, C.; POWER, T.; RENNÓ, L. Opinião pública, estratégia presidencial e ...

opção presidencial pelo decreto aumenta sua popularidade. Mais adiante, no entanto, o aumento da popularidade reduz a necessidade de apelar a meios extraordinários de governar e induz a uma estratégia mais rotineira de envio de leis ordinárias ao congresso.

Esses resultados moderam a idéia de que não há sensibilidade e que as ligações de representação entre eleitores e autoridades eleitas são fracas no Brasil. Primeiro, encontramos alguns indícios, embora fracos e inconsistentes, de que a popularidade afeta as escolhas dos políticos, embora principalmente de forma reativa. Em outras palavras, a popularidade presidencial não precede as escolhas dos políticos, mas estes parecem prestar atenção à reação do público e isso afeta suas ações futuras. Em segundo lugar, os presidentes brasileiros não decidem num vácuo. Como Pereira, Power e Rennó (2005) mostram, as escolhas presidenciais de instrumentos de elaboração de políticas são influenciadas pelo ambiente no congresso. Há freios e contrapesos entre os poderes do Estado no Brasil e estes são, com freqüência, processados por meio dos acordos políticos necessários ao funcionamento do presidencialismo de coalizão (ABRANCHES, 1988).

\section{Referências Bibliográficas}

ABRANCHES, S. Presidencialismo de coalizão: o dilema institucional brasileiro. Dados, v. 31, n. 1, p. 5-38, 1988.

AMES, B. The deadlock of democracy in Brazil. Ann Arbor: University of Michigan Press, 2001.

AMORIM NETO, O. Presidential cabinets, electoral cycles, and coalition discipline in Brazil. In: MORGENSTERN, S.; NACIF, B. (ed.). Legislative politics in Latin America. New York:

Cambridge University Press, 2002.

AMORIM NETO, O. et al. Agenda power in Brazil's Camara dos Deputados, 1989-98. World Politics, n. 55, p. 550-578, jul. 2003.

BREHM, J. The phantom respondents. Ann Arbor: University of Michigan Press, 1993. 
DENZAU, A. T.; MUNGER, M. C. Legislators and interest groups: how unorganized interests get represented. American Political Science Review, v. 80, n. 1, p. 89.106, 1986.

DORNBUSCH, R.; EDWARDS, S. The macroeconomics of populism. In: DORNBUSCH, R.; EDWARDS, S. (ed.) The macroeconomics of populism in Latin America. Chicago: The University of Chicago Press, 1991.

EDWARDS, G.; WOOD, B. D. Who influences whom? The president and the public agenda. American Political Science Review, v. 93, n. 2, p. 327-344, 1999.

FIGUEIREDO, A.; LIMONGI, F. Executivo e legislativo na nova ordem constitucional. Rio de Janeiro: Fundação Getúlio Vargas, 1999.

FRANCIS, W.; KENNY, L. Position shifting in pursuit of higher office. American Journal of Political Science, v. 40, n. 3, p. 768-786, 1992.

JOHNSON, G.; CRISP, B. Mandates, powers, and policies. American Journal of Political Science, v. 47 , n. 1, p. $128 \cdot 142,2003$.

KALT, J. P.; ZUPAN, M. A. Capture and ideology in the economic theory of politics. American Economic Review, v. 74, n. 3, p. 279-300, 1984.

HAGGARD, S.; KAUFMAN, R. Economic adjustment and the prospects for democracy. In: HAGGARD, S.; KAUFMAN, R. (eds.). The politics of economic adjustment. Princeton: Princeton University Press, 1992.

LEWIS-BECK, M. Economics and elections: the major western democracies. Ann Arbor: The University of Michigan Press, 1988.

MAINWARING, S. Politicians, parties, and electoral systems: Brazil in comparative perspective. Comparative Politics, v. 24, n. 1, p. 21-43, 1991.

MANIN, B. Principles of representative government. Cambridge: Cambridge University Press, 1997.

NORDHAUS, W. The political business cycle. Review of Economic Studies, v. 42, p. 169-190, 1975.

O’DONNELL, G. Delegative democracy. Journal of Democracy, v. 5, n. 1, p. 55-69, 1994. 
PEREIRA, C.; POWER, T.; RENNÓ, L. Under what conditions do presidents resort to decree power? Theory and evidence from the brazilian case. Journal of Politics, v. 67, n. 1, 2005.

PITKIN, H. The concept of representation. Berkeley: University of California Press, 1967.

PRZEWORSKI, A. The state and the citizen. 1998. Trabalho apresentado no Seminário Internacional sobre Sociedade e a Reforma do Estado, São Paulo, 26-28 de março 1998.

PZREWORSKI, A.; STOKES, S.; MANIN, B. (ed.). Democracy, accountability, and representation. New York: Cambridge University Press, 1999.

ROTHENBERG, L.; SANDERS, M. Severing the electoral connection: shirking in the contemporary congress. American Journal of Political Science, v. 44, n. 2, p. 316-325, 2000.

SPILLER, P. Politicians, interest groups, and regulators: a multiple-principals agency theory of regulation, or 'let them be bribed'. Journal of Law and Economics, v. 1, p. 65-101, 1990.

STIGLER, G. The theory of economic regulation. Bell Journal of Economics, v. 2, p. 3-21, spring 1971.

STOKES, S. Political support for market reforms in new democracies. New York: Cambridge University Press, 2001 a.

. Mandates and democracy: neoliberalism by surprise in Latin America. Cambridge:

Cambridge University Press, 2001b.

WEYLAND, K. Neopopulism and neoliberalism in Latin America: unexpected affinities. Studies in Comparative International Development, v. 31, n. 3, p. 3.31, 1996.

Uma versão preliminar deste artigo foi apresentada no encontro da LASA em Las Vegas de 7 a 10 de outubro de 2004. Gostaríamos de agradecer a Chappell Lawson por valiosos comentários.

Recebido para publicação em março de 2005. Aprovado para publicação em setembro de 2005.

Tradução de Pedro Maia Soares. 